\section{Commentary: Hyperglycemia during myocardial infarction: Can sound waves improve outcomes?}

\author{
Frank W. Sellke, MD
}

Diabetes is increasing not only in North America but across the world. It is well-known that diabetes is associated with an increased incidence of myocardial infarction and both cardiovascular and all-cause mortalities. In the setting of either ST-segment or non-ST segment myocardial infarction, poor glycemic control in patients with diabetes and stress hyperglycemia in patients without diabetes is associated with worse outcomes. ${ }^{1}$ It is not clear whether tight glycemic control during acute myocardial infarction improves outcome, ${ }^{2}$ however, or even whether hyperglycemia leads to increased ischemic injury or is truly a cause of the worse outcome. It may just be a marker of illness. Indeed, there are other studies that have not found an injurious effect of hyperglycemia in the setting of myocardial infarction, and there are some studies that find a reduction in infarct size in the setting of hyperglycemia ${ }^{3}$ related to increased expression of cell survival proteins. It is therefore clear that we really do not have a good handle on the effects of hyperglycemia on myocardial infarction, except that hyperglycemia is a marker of poor outcome in the setting of myocardial infarction.

In this issue of the Journal, Charles and colleagues ${ }^{4}$ report their examination of a novel method that potentially could reduce the hyperglycemia-induced exacerbation of myocardial ischemia reperfusion injury, pulsed ultrasound. In a previous study by this group, Gigliotti and colleagues ${ }^{5}$ found that acute hyperglycemia induced splenic leukocytes and that pulses ultrasound inhibited this effect. Gigliotti and colleagues ${ }^{5}$ concluded that there was a causal relationship between splenic leukocytes and infarct size, and that the pulsed ultrasound-induced reduction in infarction was

\footnotetext{
From the Division of Cardiothoracic Surgery, Alpert Medical School of Brown University and Rhode Island Hospital, Providence, RI.

Funding was provided by grants RO1 HL46716, P20 GM 103652, and RO1 HL128831.

Disclosures: Author has nothing to disclose with regard to commercial support.

Received for publication Oct 18, 2019; revisions received Oct 18, 2019; accepted for publication Oct 18, 2019; available ahead of print Oct 31, 2019.

Address for reprints: Frank W. Sellke, MD, Division of Cardiothoracic Surgery, Alpert Medical School of Brown University and Rhode Island Hospital, 2 Dudley St, MOC 360, Providence, RI 02905 (E-mail: fsellke@ lifespan.org).

J Thorac Cardiovasc Surg 2021;161:e307-8

$0022-5223 / \$ 36.00$

Copyright (c) 2019 by The American Association for Thoracic Surgery https://doi.org/10.1016/j.jtcvs.2019.10.094
}

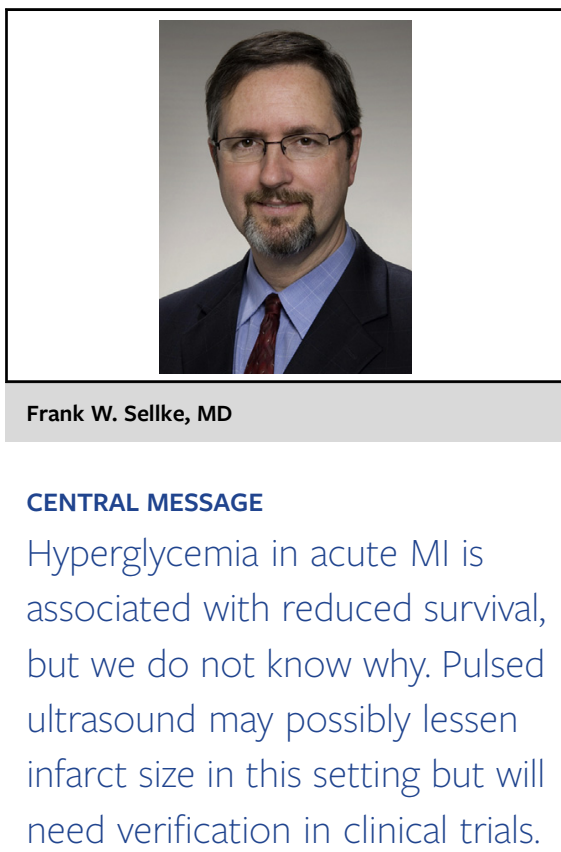

mediated by an anti-inflammatory mechanism acting on the splenic leukocytes. In the current study, Charles and colleagues ${ }^{4}$ found that the application of pulsed ultrasound, either in the area of the spleen or in the neck, reduced infarct size by two-thirds. In mice that had undergone vagotomy, the benefit disappeared, and it was not evident in knockout mice for the acetylcholine receptor, suggesting that the effect is related to a cholinergic mechanism.

This is an interesting and well-executed study, but there are several pieces of information that are missing. First, what is the role of splenic leukocytes in infarct size? The mechanisms of myocardial injury in the setting of ischemia-reperfusion include complement, oxygenderived free radicals, protein denaturation, and many other mechanisms, including activation of leukocytes. There have been many trials attempting to reduce infarct size, but nearly all have had negative results. Second, the study was performed in mice, which are known to be different from larger animals and certainly from human patients. Third, the model was somewhat artificial, in that the ischemic period was 30 minutes, followed by a very brief period of reperfusion. Patients presenting with an acute myocardial infarction generally have had pain for a longer period. Another consideration is the utility of pulsed ultrasound in limiting infarct size in patients. I am personally skeptical that this will show any benefit in patients, but ultrasound is noninvasive and associated with little risk of injury, so why not give it a try. After all, there are other methods to reduce myocardial ischemia, such as external lower extremity compression, that probably work and are 
used in parts of Asia, and we certainly do not have all the answers there either.

\section{References}

1. Deckers JW, van Domburg RT, Akkerhuis M, Nauta ST. Relation of admission glucose levels, short- and long-term (20-year) mortality after acute myocardial infarction. Am J Cardiol. 2013;112:1306-10.

2. Malmberg K, Rydén L, Wedel H, Birkeland K, Bootsma A, Dirkstein K, et al; DIGAMI 2 Investigators. Intense metabolic control by means of insulin in patients with diabetes mellitus and acute myocardial infarction (DIGAMI 2): effects on mortality and morbidity. Eur Heart J. 2005;26:650-61.

3. Chu LM, Osipov RM, Robich MP, Feng J, Oyamada S, Bianchi C, et al. Is hyperglycemia bad for the heart during acute ischemia? J Thorac Cardiovasc Surg. 2010;140:1345-52.

4. Charles EJ, Tian Y, Zhang A, Wu D, Mehaffey JH, Gigliotti JC, et al. Pulsed ultrasound attenuates the hyperglycemic exacerbation of myocardial ischemiareperfusion injury. J Thorac Cardiovasc Surg. 2021;161:e297-306.

5. Gigliotti JC, Huang L, Bajwa A, Ye H, Mace EH, Hossack JA, et al. Ultrasound modulates the splenic neuroimmune axis in attenuating AKI. J Am Soc Nephrol. $2015 ; 26: 2470-81$.
See Article page e297.

\section{Commentary: The new kid in town: Pulsed ultrasound to prevent ischemia-reperfusion injury}

\author{
Friedhelm Beyersdorf, MD
}

Ischemia-reperfusion injury (IRI) is a major clinical problem in all fields of medicine, especially in cardiac surgery and cardiology. Major improvements in understanding the pathophysiology, the causes, and the consequences have been achieved over the last decades. ${ }^{1-3}$ Charles and colleagues ${ }^{4}$ from Irving Kron's group in Charlottesville are to be congratulated for drawing our attention to a new nonpharmacologic, noninvasive therapy option to reduce infarct size during acute myocardial infarction (MI). They provide promising data that pulsed ultrasound (pUS) is capable of attenuating the hyperglycemic exacerbation of myocardial IRI via the cholinergic anti-inflammatory pathway. ${ }^{4}$

Acute hyperglycemia in patients with MI (1) is independently associated with greater mortality and larger infarct size $^{5}$ and (2) leads to the stimulation of splenic leukocytes through activation of the nicotinamide adenine dinucleotide

From the Department of Cardiovascular Surgery, University Heart Center FreiburgBad Krozingen, and Albert-Ludwigs-University Freiburg, Freiburg, Germany.

Disclosures: Dr Beyersdorf is founder and shareholder of the start-up company "Resuscitec" of the University of Freiburg, Germany.

Received for publication Nov 4, 2019; revisions received Nov 4, 2019; accepted for publication Nov 4, 2019; available ahead of print Nov 27, 2019.

Address for reprints: Friedhelm Beyersdorf, MD, Department of Cardiovascular Surgery, University Heart Center Freiburg-Bad Krozingen, Hugstetterstr. 55, D-79106 Freiburg, Germany (E-mail: friedhelm.beyersdorf@uniklinik-freiburg.de).

J Thorac Cardiovasc Surg 2021;161:e308-9

$0022-5223 / \$ 36.00$

Copyright (c) 2019 by The American Association for Thoracic Surgery

https://doi.org/10.1016/j.jtcvs.2019.11.019
Check for updates

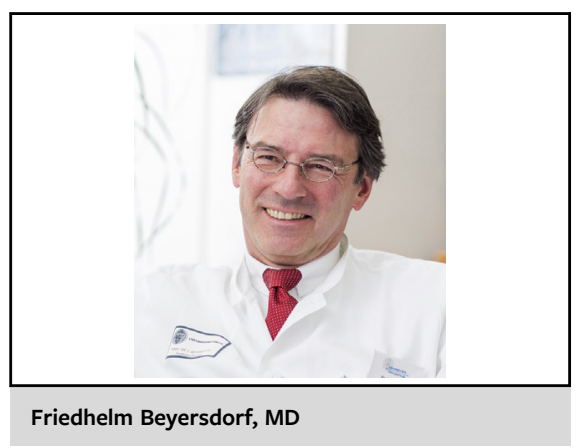

CENTRAL MESSAGE

Pulsed ultrasound is a promising new approach to limit ischemiareperfusion-injury.

phosphate oxidase pathway, which plays an important role in leukocyte-mediated reperfusion injury. ${ }^{6}$ Interestingly, reports show that pUS modulates splenic leukocytes into an anti-inflammatory phenotype.

The strength of the study is that the authors not only report a significant reduction in infarct size in mice with acute hyperglycemia and 20 minutes of regional ischemia followed by 60 minutes of reperfusion, but that they provide insight into the molecular mechanisms of these beneficial effects. Splenic and neck pUS seem to reduce the splenic inflammatory response associated with hyperglycemic exacerbation of MI through vagus and acetylcholine signalling. 4

The authors also point out 2 additional significant elements: (1) if neck pUS was applied 24 hours before IRI, it was as protective as if applied just before coronary occlusion; (2) when neck pUS was performed 10 minutes after 